\title{
Simulação na formação e na qualificação do profissional de enfermagem
}

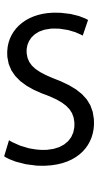

imulação é uma pedagogia que utiliza um ou mais estratégias para promover, melhorar ou validar conhecimentos dos participantes por meio da aprendizagem baseada na experiência'. É um processo dinâmico que envolve a criação de uma situação hipotética que incorpora uma representação autêntica da realidade; facilita a participação ativa do aluno - estudante e profissional - e integra as complexidades do aprendizado prático e teórico com oportunidades para o embasamento teórico, o desenvolvimento de competências observado por um checklist durante a prática clínica simulada e o debriefing, que seria o momento de reflexão e discussão. Ela pode ser denominada simulação robótica, cênica, com uso de atores ou pacientes padronizados e virtual. A simulação robótica pode ser desenvolvida com simuladores de baixa fidelidade: (manequins estáticos), média fidelidade (como os que possuem sons pulmonares e cardíacos, porem sem expansividade torácica e com interação limitada) e alta fidelidade (com respiração espontânea, expansibilidade torácica, sons cardíacos pulmonares, fala, interação e respostas fisiológicas próximas as reais). Os cenários de simulação aproximam o aluno da realidade da profissão, valorizando-se a oportunidade de rever os erros que podem ser evitados em situações semelhantes no futuro, aumentando a segurança do aluno e do paciente ${ }^{2}$.

$\mathrm{Na}$ formação dos profissionais, três pilares norteiam o processo de ensino-aprendizagem da simulação: treinamento realizado em ambiente seguro e controlado, foco no profissional e não mais no paciente, e possibilidade de praticar habilidades comportamentais e desenvolver consciência crítica ${ }^{3}$. Logo, inserir essa metodologia de ensino à formação dos profissionais de enfermagem, pretende impactar positivamente a sua qualificação, nos diversos níveis de atenção à saúde da população, desenvolvendo a implementação das melhores práticas, de atitudes éticas e de responsabilidade profissional e interdisciplinar. Essa inserção requer que escolas e instituições de saúde agreguem, aos seus laboratórios de habilidades, ambientes que representem o contexto de trabalho - entre estes por exemplo, o domicílio dos usuários, os ambulatórios, as unidades básicas de saúde, o atendimento pré hospitalar e os diferentes cenários do cuidado que compõe um hospital. Para tanto, faz-se necessário construir uma cultura do real significado de simulação, considerando que a chave do sucesso em simulação clínica não se sustenta somente em equipamentos de alta tecnologia, mas na capacitação dos professores, denominados nessa tecnologia de ensino como facilitadores, possibilitando a execução exitosa de um modelo de desenvolvimentos de competências e juízo clínico em enfermagem.

Nesse contexto, a simulação pode ser utilizada no âmbito profissional como uma ferramenta para a Educação Permanente em Saúde (EPS), como uma estratégia do Sistema Único de Saúde (SUS), cujo objetivo é a transformação das práticas profissionais e da própria organização do trabalho, tomando, como referência, as necessidades de saúde das populações e a organização da gestão setorial. O pressuposto é capacitar e aprimorar habilidades dos profissionais da saúde para atenderem as reais necessidades da população embasados nos princípios do SUS. Assim, urge valorizar a simulação, como metodologia inovadora e motivadora, tornando-a possível de ser utilizada na EPS nos serviços de saúde

Mara Ambrosina de Oliveira Vargas ${ }^{1}$

Editora Associada

\section{Referências:}

1. Meakim C, Boesi T, Decker S, Franklin AE, Gloe D, Lioce L et al. Standards of Best Practice: Simulation Standard I: Terminology. Clinical Simulation in Nursing, 2013, 9(65); p.S3-S11.).

2. Teixeira CRS, Pereira MCA, Kusumota L, Gaioso VP, Mello CL, Carvalho EC. Avaliação dos estudantes de enfermagem sobre a aprendizagem com a simulação clínica. Rev. Bras. Enferm 2015, 68(2). Available from: http://www.scielo.br/scielo.php?script=sci_ arttext\&pid=S0034-71672015000200311.

3. Araújo ALLS, Quilici AP. O que é simulação e por que simular. In: Quilici AP. Simulação Clínica: do conceito à aplicabilidade. São Paulo: Editora Atheneu, 2012. 1-16.

4. BRASIL. Ministério da Saúde. Secretaria-Executiva. Secretaria de Gestão do Trabalho e da Educação na Saúde. Glossário temático de gestão do trabalho e da educação na saúde. Brasília: SGTES, 2007. 